\title{
Measuring Reference Price Formation: Analysis In A Virtual Experimental Context
}

Juan-Antonio Mondéjar-Jiménez, University of Castilla-La Mancha, Spain

Manu Carricano, Inseec-Paris, France

José Mondéjar-Jiménez, University of Castilla-La Mancha, Spain

\begin{abstract}
As many surveys stated, companies are investing in better pricing processes, tools and capabilities. Among these companies, $42 \%$ consider that capturing the full value of products and services is one of the top challenges related to price setting and optimization. In addition, many improvements have been made recently in the way companies set an optimal price level and adapt their pricing processes. However, pricing decision-makers have to face a paradox: price setting is a left-brained (rational) process, whereas price perceptions and evaluations are right-brained (subjective). Tools available to solve this paradox are limited. Direct measures (price tresholds,...), Van Vestendorp's PSM approach, conjoint measurement can be useful in assessing price evaluations but fail in measuring how consumers compare, evaluate and memorize price offers. Reference price, viewed as a standard against which the purchase price of a product is judged (Monroe, 1973), is one of the most studied constructs in research on strategic pricing decisions. As Kalyanaram and Winer (1995) stated, "reference price is a psychological construct which, when incorporated into normative models, can change the way marketing managers make decisions about price and promotions". One stream of research has identified antecedents of reference price and has assessed their effects through experimentation, others have reported effects of reference price models on brand choice and other purchase decisions (Mazumdar et al. 2005). Many studies have examined and called for greater integration of different measures of reference price, noting that the research area is highly context specific (Lowe and Alpert, 2007). The purpose of this research is to operationalize a tool to measure and control contextual influences on reference price formation using a simulated experiment. The decision environment is generated and controlled in a lab setting using a software that simulates a purchase decision context and records the behaviours induced by that process. Contextual and temporal influences can be measured monitoring the total amount of information consulted for competing products (attributes and prices), as well as the time spent on information search. More specifically, this research evaluates the impact of search effort on the perceived reference price in the market at different points in time in the decision process.
\end{abstract}

\section{THE CONCEPT OF REFERENCE PRICES AND ITS MEASURES}

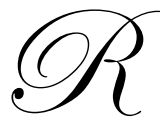

esearch on reference price sheds light on consumers' price perception process and price evaluation. The basic assumption is that this process depends on a comparison between current market prices and an internal reference price (Kalyanaram and Winer, 1995; Janiszewski and Lichtenstein, 1999; Bell and Bucklin, 1999; Moon and Russell, 2000). Such comparisons presumably indicate whether a price is too high or too low (Niedrich, Sharma and Wedell, 2001). Briesch, Krishnamurthi, Mazumdar and Raj (1997), in turn, differentiate between two types of reference price model: stimulus-based models (i.e., those based on the information available at the point of purchase), and memory-based models (i.e., those based on a price history and/or other contextual factors).

The theoretical concept of reference price is therefore discussed in two directions: on the one hand, the price perception, and on the other, the context of the prices coexisting when the consumer has to evaluate a price, or 
the consumer's purchase experience (Lowengart, 2002). For the same reason, Urbany and Dickson (1991) see the internal reference price as typically estimated from actual market prices, although it is necessary to determine an acceptable parameter for deciding whether the consumer is conscious of estimating the actual market prices exactly. At this point, the consumer's level of price knowledge is important to be able to establish an adequate system of reference prices (Rosa, 2004). Clearly, consumers resort to their previous knowledge to make their comparisons and, above all, their price evaluations. But it is necessary to show whether the consumers really know how to use the information that they have prior to the purchase process. Thus, Manning, Sprott and Miyazaki (2003) show that exposure to prices and the motivation to process such information is significantly related to knowledge about prices and about price usage.

On the basis of the above, we derive the folowing hypothesis:

Hypothesis 1: The consumer's reference price is higher in conditions of high search effort.

Hypothesis 2: The consumer's reference price is higher in conditions of high total time spent on products comparisons.

Hypothesis 3: The consumer's reference price is higher in conditions of high level of comparisons of existing prices.

\section{METHODOLOGY}

The virtual experiment is represented by a hypothetical, virtual market not physically identified with any geographic area. This market includes different types of store where consumers can acquire information about the different characteristics and attributes of the product and purchase the product in whatever store they choose.

The products used in the simulation are digital cameras. The starting situation for the consumers is consequently the specific choice of a product -digital camera- in the framework of an experiment simulating a real purchase. Introducing the price characteristic is precisely what allows the authors to manipulate the prices and then simulate the different experimental contexts.

The decision environment is generated and controlled in the lab using software that simulates a purchase decision context and records the behaviours induced by that process. The program also includes tools for obtaining additional information. For the simulation and recording the authors use an adaptation of the computer program SSPD (Gómez, 2001).

In addition, the simulation tool presents a series of questions to the subject periodically and automatically to measure the effects of the information acquisition process on certain cognitive-affective dimensions, and how these dimensions are updated as the process evolves. This is precisely one of the most interesting characteristics of the current research, since it allows the authors to study price perception and the associated evaluations in a dynamic way during the actual decision process.

The experiment provides information from four different time points in the purchase process. The reference price at the first time point (t1) is the consumer's criterion before beginning the purchase decision process. The reference price at time point two (three) is obtained 10 (20) minutes after starting the decision process. Finally, before ending the simulation, the program requests the consumer's reference price at the end of the process ( $t 4)$.

The sample chosen consists of students studying for their degree in Business Administration and Management. The students were divided into two equal-sized groups of 60 students each to carry out the tests.

\section{RESULTS}

In line with the hypotheses, the authors ran univariate tests for each model variable. Table 1 shows the results of this analysis. 
Table 1: Individual tests on reference price

\begin{tabular}{|c|c|c|c|c|c|c|c|c|c|c|}
\hline \multirow{2}{*}{ Factor } & \multirow{2}{*}{$\begin{array}{l}\text { Dependent } \\
\text { Variable }\end{array}$} & \multicolumn{2}{|c|}{$\mathbf{F}$} & \multicolumn{2}{|c|}{ Sig } & \multicolumn{2}{|c|}{$\eta^{2}$} & \multicolumn{2}{|c|}{ Pow } & \multirow{2}{*}{ Difference } \\
\hline & & MAN & MANC & MAN & MANC & MAN & MANC & MAN & MANC & \\
\hline \multirow{3}{*}{ REFPRICE } & $\begin{array}{l}\text { Atributes } \\
\text { screens } \\
\text { visited }\end{array}$ & 5,912 & 5,140 & 0,016 & 0,024 & 0,026 & 0,023 & 0,678 & 0,617 & $67,85(*)$ \\
\hline & $\begin{array}{l}\text { Time on } \\
\text { experiment }\end{array}$ & 3,698 & 3,491 & 0,056 & 0,063 & 0,016 & 0,016 & 0,482 & 0,460 & $105,38(* *)$ \\
\hline & $\begin{array}{l}\text { Prices } \\
\text { consulted }\end{array}$ & 3,780 & 3,341 & 0,053 & 0,069 & 0,017 & 0,015 & 0,490 & 0,444 & $6,38(* *)$ \\
\hline
\end{tabular}

According to the results, significant differences exist, which provides support for hypotheses 1,2 and 3 . The high observed power of the test, together with the confidence levels, ratify this decision, and the results obtained previously. hypothesised:

As Table 1 shows, the results show statistically significant differences in the same direction as

H1: Analysis of data measuring the search effort (number of attributes screens consulted) confirms that search effort influences an high level of reference price ( $\alpha=0,016$ MANOVA y $\alpha=0,024$ MANCOVA) ;

H2: The total time spent on the buying process also influences an high level of reference prices $(\alpha=0,056 \mathrm{y}$ $\alpha=0,063$, significant at a 0,1 level) ;

H3: The number of prices (number of views of a price attribute) also influences significantly the level of reference price $(\alpha=0,053$ y $\alpha=0,069$, significant at a 0,1 level)

In addition, this finding is verified at all four points in time where the criterion is measured dynamically.

\section{CONCLUSIONS}

Finally, the results obtained here are in line with the theoretical position taken, and provide support for the proposed hypotheses. Thus, the data indicate that individuals' purchase behaviour can show significant and interesting differences depending on whether the monetary unit is expressed in pesetas or euros, on the one hand, or whether the price dispersion in the market is low or high, on the other.

With regard to the reference price, consumers discriminate more quickly and accurately when the distance is greater, so they perceive the reference price to be higher when expressed in pesetas than when expressed in euros, which also shows the effect caused by the price dispersion of the evoked prices.

\section{AUTHOR INFORMATION}

Juan-Antonio Mondéjar-Jiménez: PhD and Degree in Business Administration by University of Castilla-La Mancha (Spain). Degree in Advanced Studies in Marketing at the same university and Master's Degree in Marketing Research at National Distance Education University of Spain (UNED). Assistant Professor in Marketing at Business Administration Department. Faculty of Social Sciences of Cuenca. University of Castilla-La Mancha (Spain).

Research Interest: Price perception, e-learning, consumer behavior and tourism marketing.

Manu Carricano: European Bussiness Programme (EBP): Master's Degree in France at Groupe Ecole Supérieure de Commerce (ESC) de Bordeaux and in Spain at Centro Europeo de Gestion de Empresas (CEGE), Madrid. 
Postgraduate degree (DEA) in management science at Montesquieu University Bordeaux with honors. Finishing a doctoral thesis at Montesquieu University, Bordeaux. Assistant Professor of Marketing at Institut des Hautes Etudes Economiques et Commerciales (INSEEC) and Head of the Marketing Major.

Research Interest: Price perception, marketing research and data analysis.

José Mondéjar-Jiménez: European $\mathrm{PhD}$ in Economics and Degree in Business Administration by University of Castilla-La Mancha. Degree in Advanced Studies in Statistics at the same university and Master's Degree in Marketing Research at National Distance Education University of Spain (UNED). Assistant Professor in Statistics at Statistics Department. Faculty of Social Sciences of Cuenca. University of Castilla-La Mancha (Spain).

Research Interest: E-learning, tourism and state-space models.

\section{REFERENCES}

1. Bell, D.R. and Bucklin, R.E. (1999). "The role of internal reference points in the category purchase decision". Journal of Consumer Research, 26 (September), 128-143.

2. Briesch, R. A.; Krishnamurthi, L.; Mazumdar, T.; Raj, S. P. (1997). "A comparative analysis of reference price models". Journal of Consumer Research, 24 (September), 212-214.

3. Gómez, M. A. (2001). "SSPD. Una herramienta informática para simular y registrar los procesos de decisión del consumidor". XIII Encuentro de Profesores Universitarios de Marketing, Málaga, Esic, 485497.

4. Janiszewski, C. and Lichtenstein, D. R. (1999). "A range theory account of price perception". Journal of Consumer Research, 25 (March), 353-368.

5. Kalyanaram, G. and Winer, R. S. (1995). "Empirical generalizations from reference price research". Marketing Science, 14 (3), 161-169.

6. Lichtenstein, D. R.; Ridgway, N. M. and Netemeyer, R. G. (1993). "Price perceptions and consumer shopping behaviour. A field study". Journal of Marketing Research, XXX, May, 234-245.

7. Lowe, B. and Alpert, F. (2007). "Measuring reference price perceptions for new product categories: which measure is best?", Journal of Product and Brand Management, 16, 2, 132-41.

8. Lowengart, O. (2002). "Reference price conceptualisations: An integrative framework of analysis". Journal of Marketing Management, 18, 145-171.

9. Manning, K.C.; Sprott, D.E. and Miyazaki, A.D. (2003). "Unit price usage knowledge: Conceptualization empirical assessment". Journal of Business Research, 56, 367- 377.

10. Mazumdar, T.; Raj, S.P. and Sinha, I. (2005). "Reference price research: review and propositions". Journal of Marketing, 69 (October), 84-102.

11. Monroe K.B. (1973). "Buyers' subjective perceptions of price”, Journal of Marketing Research, 10, 70-80.

12. Moon, S. and Rusell, G. J. (2000). "Profiling the Reference Price Consumer". Working Paper. Henry B. Tippie College of Business. Universidad de Iowa.

13. Niedrich, R. W.; Sharma, S. and Wedell, D. H. (2001). "Reference Price and Price Perceptions. A Comparison of Alternative Models". Journal of Consumer Research, 28 (December), 339-354.

14. Rosa, I.M. (2004), "Price knowledge: effects of consumers' attitudes towards prices, demographics, and socio-cultural characteristics", Journal of Product \& Brand Management, 13, (6), 406-428.

15. Urbany, J. E. and Dickson, P. R. (1991). "Consumer normal price estimation: market versus personal standards". Journal of Consumer Research, 18 (June), 45-51. 